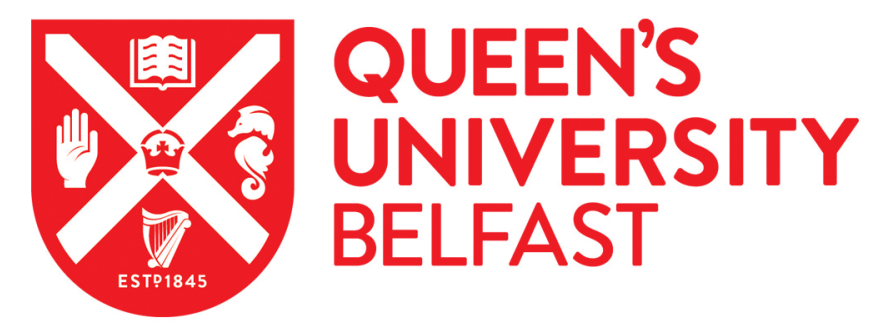

\title{
A prospective cohort on the incidence of fractures in single-implant mandibular overdentures
}

de Paula, M. S., Cardoso, J. B., de Menezes, E. E. G., Nogueira, T. E., McKenna, G., \& Leles, C. R. (2020). A prospective cohort on the incidence of fractures in single-implant mandibular overdentures. Journal of Dentistry, 103, [103521]. https://doi.org/10.1016/j.jdent.2020.103521

Published in:

Journal of Dentistry

Document Version:

Peer reviewed version

Queen's University Belfast - Research Portal:

Link to publication record in Queen's University Belfast Research Portal

Publisher rights

Copyright 2020 Elsevier.

This manuscript is distributed under a Creative Commons Attribution-NonCommercial-NoDerivs License

(https://creativecommons.org/licenses/by-nc-nd/4.0/), which permits distribution and reproduction for non-commercial purposes, provided the author and source are cited.

\section{General rights}

Copyright for the publications made accessible via the Queen's University Belfast Research Portal is retained by the author(s) and / or other copyright owners and it is a condition of accessing these publications that users recognise and abide by the legal requirements associated with these rights.

Take down policy

The Research Portal is Queen's institutional repository that provides access to Queen's research output. Every effort has been made to ensure that content in the Research Portal does not infringe any person's rights, or applicable UK laws. If you discover content in the Research Portal that you believe breaches copyright or violates any law, please contact openaccess@qub.ac.uk. 


\title{
A prospective cohort on the incidence of fractures in single-implant mandibular overdentures
}

\section{Short title: Fractures in single-implant mandibular overdentures}

Keywords: Overdenture; dental implant; prosthodontics; cohort study; fracture.

\author{
Marcella Silva de Paula ${ }^{1}$ \\ Joyce Borges Cardoso ${ }^{1}$ \\ Eunice Ellen Gontijo de Menezes ${ }^{1}$ \\ Túlio Eduardo Nogueira ${ }^{1}$ \\ Gerald McKenna² \\ Cláudio Rodrigues Leles ${ }^{1}$
}

1 School of Dentistry, Federal University of Goias, Goiania, Brazil

School of Dentistry, Federal University of Goias, Avenida Universitária esquina com $1^{a \underline{a}}$ Avenida, s/n. Setor Universitário, Goiânia, Goiás, CEP 74605-020, Brazil

2 Centre for Public Health, Queen's University, Belfast, UK

Centre for Public Health, School of Medicine Dentistry \& Biomedical Sciences, Institute of Clinical Science Block B, Grosvenor Road, Belfast, BT12 6BJ, United Kingdom

Corresponding author

\section{Cláudio R. Leles}

Faculdade de Odontologia, Universidade Federal de Goiás, Praça Universitária, s/n, Setor Universitário, 74605-220, Goiania, Goias, Brazil. +55(62)32096052, e-mail: claudio_leles@ufg.br 


\section{ABSTRACT}

Objective: Denture fracture is one of the most common complications in prosthodontics and implant overdentures are reported to be at higher risk of fractures. Therefore, the aim of this study was to assess the incidence and factors associated with the occurrence of fractures in patients treated with a single implant mandibular overdenture (SIMO) opposed by a conventional maxillary complete denture. Methods: A cohort of 152 patients, $65.1 \%$ female and $34.9 \%$ male, mean age $65.4 \pm 8.5$ years, were prospectively followed-up for a minimum of 1 year and up to 6.7 years. Patients received a single midline mandibular implant with a retention system incorporated in the overdenture: Straumann ball abutment and gold elliptical matrix $(n=37)$, Neodent ball/nylon matrix $(n=83)$, or Neodent Equator/nylon matrix $(n=32)$. Fracture was defined as a complete separation of denture parts and classified as midline fracture (over the implant region), or elsewhere. No metal reinforcement was incorporated into the overdenture. Incidence rates, life table analysis, Kaplan-Meier, and Cox regression were used for data analysis. Results: Overdenture fractures occurred in 49 patients $(32.2 \%$ incidence), with repeated fractures in 16 patients. The majority of fractures were associated with function (42.6\%) or due to the overdenture being dropped (36.8\%). Overall incidence density was 0.14 fracture/patient/year. The risk of fracture was associated with the duration of the overdenture use $(H R=0.84$; 95\% $\mathrm{Cl}=0.71-0.99)$. Conclusion: Midline denture fracture was a common complication in patients receiving SIMO treatment regardless of the implant / retention system. The use of metal reinforcement may be considered to reduce the risk of recurrent fractures.

Clinical Significance: This clinical prospective study showed that single-implant mandibular overdentures are at high risk of midline fractures. Proper post-insertion monitoring and the identification and management of patient's individual risk factors are essential for the successful treatment in the long-term.

Keywords: Overdenture; dental implant; prosthodontics; cohort study; fracture. 


\section{INTRODUCTION}

Denture fracture is one of the most common complications in prosthodontics, however there is currently limited evidence on overall incidence and predisposing factors. Fractures are mainly associated with denture base deformation due to stress resulting from poorly fitting dentures or uneven occlusal forces, dentures being dropped, and material breakdown due to processing failures [1]. Previous retrospective studies have reported incidences of denture fracture ranging from $10.2 \%$ [2] up to $26 \%$ [3] in complete denture wearers. It has been suggested that complete dentures opposing a partially dentate arch have a higher risk of complications, including denture fracture [2].

The midline is the most frequent location for a denture fracture, potentially due to the initiation and propagation of a crack in the presence of localized stress, such as the deep notching at the midline frenum [1]. In implant overdentures, the force distribution is altered as the stresses become concentrated around the retentive system components and the implant-abutment region acts as a fulcrum around which the overdenture rotates during function thus increasing the risk of fractures in this area. However, the single-implant mandibular overdenture (SIMO) may be particularly predisposed to fracture in the midline region. This may be due to high occlusal load and stress concentration in this area, as well as the rigid bone-implant interface, the reduced thickness of the denture base adjacent to the abutment, and/or poor bonding at the interface between the metal housing and denture base [4].

The incidence of fractures in SIMO has previously been reported in a number of clinical studies [5-10], and overdenture fractures were judged as a major problem, with high incidences reported in longitudinal studies [7,11,12], ranging from $21.4 \%$ after 3 years [7] up to $41 \%$ after 5 years [11]. However, incidence rates may vary considerably across studies due to differences in clinical and laboratory procedures related to the denture fabrication, and the type of implant and retention systems used. Incidence estimates may also be influenced by methodological limitations related to retrospective assessments, small sample sizes, and relatively short follow-up periods.

Therefore, this study aimed to prospectively assess the incidence and factors associated with the occurrence of fractures of SIMO in edentulous patients wearing a conventional complete denture in the opposing arch.

\section{MATERIAL AND METHODS}

The study sample comprised consecutive fully edentulous patients referred for treatment from the local public health system to the XXXXXXXXXXXXXXXXXXXX. Participants reveived new conventional complete dentures followed by treatment with a single midline implant to retain a mandibular overdenture. Details on this prospective 
cohort of edentulous subjects has previously been reported in a number of publications which assessed the effectiveness of SIMO treatment [10,13-16]. The original protocols of these clinical studies comprised the longitudinal assessment of prosthodontic and peri-implant outcomes, including overdenture fractures. As part of the recruitment process, all subjects completed a written consent form and full ethical approval was granted by the local research ethics committee for the original studies. This report has been prepared in compliance with the EQUATOR guidelines for observational studies.

Baseline treatment for all subjects consisted of construction of a new set of conventional complete dentures, followed by the insertion of a single implant in the mandibular midline to retain an overdenture. The protocol for complete denture fabrication included preliminary impressions with irreversible hydrocolloid, zinc-oxide eugenol paste for final impression, and acrylic resin artificial teeth (Trilux, Dental Vip Ltda, Pirassununga, São Paulo, Brazil) arranged in balanced bilateral occlusion. All complete dentures were processed using conventional laboratory techniques for denture fabrication including heat-cured denture base processing. No metal reinforcement of the overdenture was provided.

Three different types of implant/attachment systems were used in the study sample: (Type I) $3.75 \mathrm{~mm}$ diameter external hexagon implants with a nitrite-coated titanium ball attachment and nylon matrix (Neodent Implants, Curitiba, Brazil); (Type II) $3.75 \mathrm{~mm}$ diameter morse-taper implant with a "stud" type Equator attachment and nylon matrix (Neodent Implants, Curitiba, Brazil); and (Type III) Straumann Standard Plus SLActive ${ }^{\circledR}$ regular neck implant with a $3.4 \mathrm{~mm}$ retentive titanium anchor abutment and the corresponding elliptical gold matrix (Institute Straumann AG, Basel, Switzerland). The loading protocol included cases with either immediate, early, or conventional loading. Incorporation of retentive inserts was performed using a direct intraoral pickup technique with self-curing acrylic resin (Duralay, Reliance Dental, USA).

Patient follow-up for recording of the occurrence of fracture was initiated after incorporation of the overdenture attachment. In cases of immediate implant loading, incidences were estimated after the removal of the temporary reline material and denture rebase, when applied. All participants were reviewed regularly for assessment of longitudinal peri-implant and prosthodontics outcomes through programmed recall appointments. Regular maintenance including adjustment and replacement of the retentive inserts of the overdenture were provided as part of the study. Unscheduled visits were also accomodated to manage denture fractures or any other prosthodontic complications. Data collection extended until February, 2020.

The primary outcome measure for this study was SIMO fracture, defined as the complete separation of the denture parts, reported by the patient, and confirmed clinically. The fracture was classified according to its location: midline region (over the implant/metal housing site) or elsewhere (not over the implant region). In addition, the patient-reported reason for the occurrence of the fracture was recorded. For the purposes of this study, acrylic teeth fractures, fractures of the maxillary denture, and 
minor fractures of the denture flange were not regarded as SIMO fracture and therefore were excluded from the data analysis.

Clinical data were also gathered to assess potential risk factors for the incidence of fractures, including patient age and gender, time of SIMO in function, morphology of the anterior ridge [17], and the type of implant and retentive system.

Data analyses included descriptive statistics of the treatment provided and potential fracture risk factors. Overall incidence rate and incidence density were estimated for the entire follow-up period. For calculation of the incidence density (number of new cases per the sum of the person-time of the at-risk population), the total person-time (in years) was considered.

A subsequent analysis using the life table method was performed by constructing a summary table that subdivided the period of observation into smaller time intervals (yearly). The probability from each of the yearly intervals was estimated based on the assumption that the probability for the event of interest (SIMO fracture) depends only on time, and that cases that enter the study at different times should behave similarly, and no systematic differences exist between censored and uncensored cases. A series of parameters related to the occurrence of the terminal event (incidence), survival rates, and hazard rates were provided for each of the consecutive intervals.

Kaplan-Meier analysis and Cox Proportional Hazard regression models were also used to estimate the survival function and test the influence of independent factors on the time to SIMO fracture. The significance level was set at 0.05, with IBM-SPSS 24.0 software used for all statistical analyses.

\section{RESULTS}

One hundred and fifty-two patients were prospectively followed and included in this analysis, $65.1 \%(n=99)$ female and $34.9 \%(n=53)$ male, with an age range from 47 89 years (mean=65.4; $S D=8.5$ ). The length of follow-up, corresponding to the time of SIMO use, ranged from 1 to 6.7 years (mean=2.7; $S D=1.8$ ). Table 1 shows the main features of the study patient sample and SIMOs.

Table 2 details the main characteristics of the fracture events, including the reasons and time for fracture occurrence, frequency of recurrent fractures, and position of the fracture line. Forty-nine participants $(32.2 \%)$ had a SIMO fracture during the course of the study. Of the 49 patients who fractured their SIMO, 16 (10.6\%) had more than one fracture during the follow-up period. As some participants had recurrent fractures, a total of 68 fractures occurred during the overall follow-up period. The overall incidence density was $0.14(13.9 \%)$ fracture events per patient/year. The most frequently reported reason for fracture was during oral function (46.2\%), followed by dropping 
the denture (36.8\%), usually when cleaning. The most frequent fracture site was the midline region near or over the retentive housing (86.8\%). Figure 1 shows a typical case of fractured overdenture in the midline area. The line of fracture resulted in a complete separation of the acrylic resin from the metal housing and no residual acrylic resin remained in the metal housing interface. In most of the cases, the housing was not completely detached from the overdenture.

The life table analysis in Table 3 illustrates the number of patients, incidences, and the estimated risks for occurrence of fracture events at different time points during the course of a 1-year interval until the last follow-up period. Considering that the incidence rates of fractures decrease with time as influenced by the progressive reduction in the number of patients exposed to risk, the "proportion terminating" column shows the ratio of terminal events across the time intervals, which reveal fracture rates which range from 0.15 to $0.21(15-21 \%)$ until the 4-year follow-up interval, and a decrease in the following years. Moreover, the probability of a patient having a fractured overdenture during the annual intervals from 0 to 4 years of followup remained stable at around $1 \%$, ranging from 0.012 to 0.010 , and decreased to 0.003 from 5 to 6 years of follow-up.

Figure 2 shows the hazard rate $(\mathrm{HR})$ function represented in a linear scale, describing the instantaneous chance of fracture occurrence plotted against the annual time points on the $\mathrm{X}$-axis, assuming that no fracture occurred at the start of the interval. The graph shows that the hazard rate changes over time, with a progressive increase from the initial 1-year interval (Hazard Rate $=0.013$; Standard Error $=0.003$ ) until the third year of overdenture use (Hazard Rate $=0.019$; Standard Error $=0.007$ ), followed by a substantial risk decrease in the following years. This means that patients are at higher risk of fracture in the first years of overdenture use, and the chance of fracture is reduced in the subsequent years.

A Kaplan-Meier analysis in Figure 3 shows the survival function of cases according to the context reported by the patient for the occurrence of overdenture fracture. No differences were found ( $p=0.389$; Log-rank test) for fractures occurring during oral function, denture dropping, or improper handling. Furthermore, the effect of patient variables upon the time for fracture incidence was assessed using Cox regression (forward stepwise method) and reported as Hazard Ratios. No significant effects were found for patients' age $(p=0.263)$, gender $(p=0.686)$, ridge form $(p=0.532)$ and type of retention system $(p=0.341)$. A significant association was observed for the follow-up time (Hazard Ratio $=0.84 ; 95 \% \mathrm{Cl}=0.71-0.99 ; p=0.039$ ), which means that for every additional year of overdenture use, the risk of fracture falls by $16 \%$.

\section{DISCUSSION}

This study confirms previous reports of high incidences of fractures in mandibular overdentures retained by a single midline implant [7,10,18-21]. Incidence and risk 
estimates were based on a large prospective cohort with a follow-up period ranging from 12 to 80 months. The overall incidence of fractures was 32.2\% (49 out of 152 patients), and it was estimated that the proportional number of new cases of fractures is approximately $14 \%$ of the sample by year.

Although comparisons with other longitudinal studies is difficult due to differences in clinical protocols, sample size, and length of the follow-up period, these results are similar to others. A study by Kern et al. [12] reported an incidence of 47 fractures in the midline and between the canines (including 158 patients from two groups of implant loading) after a two-year follow-up of patients receiving SIMO with a ball attachment, which corresponds to $0.15(14.9 \%)$ fractures patient/year. A retrospective study by Gonda et al. [7] reported nine single-implant subjects (out of a sample of 42) with 11 fractures $(21.4 \%$ incidence over a follow-up period varying from 17 to 58 months). Bryant et al. [11] observed 22 fractures in 12 patients (41\%) in a sample of 29 patients with SIMO followed for up to 5 years. Fracture incidences in SIMO groups were similar to the 2-implant overdenture groups in the study by Gonda et al. [7], and significantly higher than the study by Bryant et al. [11].

Time-to-event estimates were not influenced by the reason for fracture occurrence, whilst the significant follow-up time variable suggests that the likelihood of fracture occurrence decreases with time for the patient without an overdenture fracture. It also explains the tendency for recurrent fractures for some patients, especially when no reinforcement is provided after the initial fracture event.

The occurrence of fracture during function or positioning over the attachment can be related to the changes in occlusal stress distribution when the overdenture is in its position in the patient's mouth. The implant-abutment region may act as a fulcrum over which the overdenture rotates during function, increasing the risk of fractures in this area. A SIMO also presents different denture kinetics compared to a 2-implant overdenture, since rotational movements are not limited to a single axis when occlusal forces are applied [22,23]. In addition, the overdenture is primarily supported by a resilient mucosal tissue, in contrast to the rigid support in the implant region due to the absence of a cushioning structure around the implant, which may lead to stress concentrations over the attachment and an increased risk for midline fracture of the denture base [24].

These mechanical factors contribute to the higher incidence of fractures in the midline area around the implant (86.8\% of fractured overdentures), potentially due to the combination of high-stress concentrations and the reduced thickness of the prosthesis base in the attachment area. These factors make the midline region the most susceptible point for crack-initiation and subsequent fracture. Nevertheless, since in all cases the housings were incorporated into the patient's existing denture using an intraoral pick-up technique, the acrylic resin thickness around the housing area may vary greatly across patients and result in very thin acrylic resin sections in some cases, when a recontour of the overdenture base may be needed. 
The propagation of pre-existing micro-cracks in the denture base can also be an initiating factor for fractures occurring during function, which was the most frequently reported reason for fracture $(42.6 \%$ of fractured overdentures). Fracture while functioning may be due to occlusal overload and the subsequent propagation of cracks due to the bending forces around the implant fulcrum point. This is most pronounced during chewing or when inserting the prosthesis by clenching the teeth. Ultimately this may lead the implant-retained prostheses to be more susceptible to fracture due to occlusal forces. Occlusal overload is also considered one of the major causes of early implant bone loss [25], and special caution should be taken for patients with a single implant for overdenture retention, including the need for regular recall visits for assessment of appropriate occlusal relations, and maintenance of adequate mucosal and implant support.

Another potential factor that might contribute to weakening the SIMO in the midline region is the protocol used to incorporate the retentive inserts onto the denture. In this study, a chairside protocol was used by creating a relief space in the inner part of the denture and the housing was incorporated directly with self-curing acrylic resin. An invitro laboratory study [26] and other clinical prospective studies [5,11] reported the use of a laboratory heat-polymerized acrylic resin reline instead of a direct technique which may increase the resistance to fracture of the overdenture in the midline area.

Patient factors such as age and gender were not associated with an increased risk of fractures. Nevertheless, age-related features could be explored more deeply, since accidental denture dropping usually when cleaning the dentures, was the second most prevalent reason for fracture. Both the cleaning and the insertion/removal of the overdenture require reasonable manual dexterity and visual acuity, and the patient's ability to handle the overdenture may vary according to the design/mechanism of the retention system. In addition, as older patients become dependent they may suffer from sensorimotor impairment, leading to limitations in manual dexterity, with subsequent impacts on their daily activities [27]. Consequently, older patients may struggle with fine dexterity and ability to handle small objects with precision and agility $[27,28]$. These aspects, associated with a decline in visual acuity [29], may explain the high number of fractures due to denture dropping.

No significant differences in the risk of fracture incidence according to the different attachment systems used in this study were observed. However a previous systematic review [30] suggested that ball attachments were associated with higher rates of overdenture fracture of SIMO, when compared to locator abutments, potentially due to the use of thin denture bases with highly retentive and large diameter ball abutments. However, the heterogeneity of clinical features makes difficult any meaningful analysis of the effects of the various factors determining the rates of fractures and the overall success of the treatment [30]. 
A fractured SIMO, even after being repaired with self-cure acrylic resin, is likely to be susceptible to the occurrence of a further fracture due to the presence of a bonding interface. In this study, the incidence of recurrent fractures was high in 16 patients $(10.5 \%)$, although no form of reinforcement of the overdenture base was performed, even after a fracture event. The reinforcement over the coping top and the midline region reduces the stress beneath the loading side of the denture and distributes the stress of the residual alveolar ridge area widely [31]. Different types of the denture base reinforcement are reported in the literature, such as an augmentation of the bulk of acrylic resin at the midline region, the use of a cast metal framework [32], the inclusion of chrome-cobalt reinforcing wire [31], the inclusion of glass fiber waves under the retention system [4] or the use of a high impact acrylic resin [33]. These strategies have the potential to increase the flexural resistance of the denture base and to promote a better distribution of occlusal forces, avoiding the accumulation of tensions in the midline area and, consequently, reducing the risk of fractures. Additional longitudinal studies comparing reinforced and non-reinforced SIMOs are needed to confirm the effectiveness of this approach in reducing the incidence of fractures in the long-term as all come at an increased cost.

A limitation of this study was the failure to assess other relevant individual risk factors that could influence the fracture incidence and the management of clinical complications. For example, patient and prosthodontic factors such as occlusal force and contact distribution, fitting of the denture to the supporting tissues, manual dexterity and handgrip force, denture base contour, and volume, among others would be useful for assessment of individual risks.

In addition, the metal reinforcement of fractured overdentures may have prevented recurrent events. Kern et al. [12] reported that all patients in their study who experienced a second fracture of the SIMO were offered a metal framework to support the implant area [12]. This appears to be a promising approach, especially for individuals presenting repeated fracture events. Moreover, although our study observed a rather high rate of patients experiencing a fracture, and some of them presenting recurrent fractures, it was observed that nearly $2 / 3$ of the participants had no fractures. Hence, the use of metal reinforcement for all SIMO patients as an initial strategy may not be the most cost-effective option because only $1 / 3$ of patients might benefit from it. Therefore, to add a framework only in case of a fracture together with the repair would be the most recommended approach.

\section{CONCLUSION}

Midline denture fracture was a common complication associated with SIMO treatment and should be managed by the identification of individual risk factors related to the patient and prosthodontic features. Regular assessment of the denture fit and the use 
of metal reinforcement of the overdenture may be considered to reduce the risk of fractures for patients at higher risk.

\section{REFERENCES}

1. Beyli MS, Fraunhofer J A von. An Analysis of Causes of Fractures of Acrylic Resin Dentures. J Prosthet Dent. 1981; 46(3):238-241.

2. Dorner S, Zeman F, Koller M, Lang R, Handel G, Behr M. Clinical performance of complete dentures: a retrospective study. Int J Prosthodont. 2010 Sep-Oct;23(5):410-7.

3. Bilham H, Erdogan O, Ergin S, Celik M, Ates G, Geckili O. Complication rates and patient satisfaction with removable dentures. J Adv Prosthodont. 2012; 4(2):109-115.

4. Gibreel M, Lassila LVJ, Närhi TO, Perea-Lowery L, Vallittu PK. Fatigue resistance of a simulated single LOCATOR overdenture system. J Prosthet Dent. 2019 Dec;122(6):557-563.

5. Liddelow $G$, Henry $P$. The immediately loaded single implant-retained mandibular overdenture: a 36-month prospective study. Int. J. Prosthodont. 2010;23:13-21.

6. Walton JN, Glick N, Macentee MI. A randomized clinical trial comparing patient satisfaction and prosthetic outcomes with mandibular overdentures retained by one or two implants. Int. J. Prosthodont. 2009;22: 331-339.

7. Gonda T, Maeda Y, Walton JN, MacEntee MI. Fracture incidence in mandibular overdentures retained by one or two implants. J Prosthet Dent. 2010; 103:178-181.

8. Kronstrom M, Davis B, Loney R, Gerrow J, Hollender L. Satisfaction and clinical outcomes among patients with immediately loaded mandibular overdentures supported by one or two dental implants: results of a 5-year prospective randomized clinical trial. Int J Oral Maxillofac Implants. 2017; 32:128-136.

9. Alsabeeha NH, Payne AG, De Silva RK, Thomson WM. Mandibular singleimplant overdentures: preliminary results of a randomised-control trial on early loading with different implant diameters and attachment systems. Clin Oral Implants Res. 2011 Mar;22(3):330-7.

10. Nogueira TE, Aguiar FMO, de Barcelos BA, Leles CR. A 2-year prospective study of single-implant mandibular overdentures: Patient-reported outcomes and prosthodontic events. Clin Oral Implants Res. 2018;29(6):541-550.

11. Bryant SR, Walton JN, MacEntee MI. A 5-year randomized trial to compare 1 or 2 implants for implant overdentures. J Dent Res. 2015;94(1):36-43.

12. Kern M, Att W, Fritzer E, Kappel S, Luthardt RG, Mundt T, Reissmann DR, Rädel M, Stiesch M, Wolfart S, Passia N. Survival and complications of single dental implants in the edentulous mandible following immediate or delayed 
loading: a randomized controlled clinical trial. J Dent Res. 2018 Feb;97(2):163-170.

13. Nogueira TE, Esfandiari S, Leles CR. Cost-effectiveness analysis of the single-implant mandibular overdenture versus conventional complete denture: study protocol for a randomized controlled trial. Trials. 2016;17(1):533.

14. Nogueira TE, Aguiar FMO, Esfandiari S, Leles CR. Effectiveness of immediately loaded single-implant mandibular overdentures versus mandibular complete dentures: A 1-year follow-up of a randomized clinical trial. J Dent. 2018;77:43-50.

15. Nogueira TE, Schimmel M, Leles $C R$. Changes in masticatory performance of edentulous patients treated with single-implant mandibular overdentures and conventional complete dentures. J Oral Rehabil. 2019 Mar;46(3):268273.

16. Taha NEKS, Dias DR, Oliveira TMC, Souza JAC, Leles CR. Patient satisfaction with ball and Equator attachments for single-implant mandibular overdentures: A short-term randomised crossover clinical trial. J Oral Rehabil. 2020;47(3):361-369.

17. Cadwood JL, Howell RA. A classification of the edentulous jaws. Int. J. Oral. Maxillofac. Surg. 1988;17:232-236.

18. Harder S, Wolfart S, Egert C, Kern M. Three-year clinical outcome of single implant-retained mandibular overdentures--results of preliminary prospective study. J Dent. 2011 Oct;39(10):656-61 .

19. Passia N, Kern M. The single midline implant in the edentulous mandible: a systematic review. Clin Oral Invest. 2014;18(7):1719-1724.

20. Batista VES, Vechiato-Filho AJ, Santiago-Junior JF, Sonego MV, Verri FR, Santos M, Goiato MC, Pellizzer EP. Clinical viability of a single-implant mandibular overdentures: a systematic review and meta-analysis. Int J Oral Maxillofac. 2018;47:1166-1177.

21. Passia N, Wolfart S, Kern M. Ten-year clinical outcome of single implantretained mandibular overdentures- A prospective pilot study. J Dent. 2019;82:63-65.

22. Maeda Y, Horisaka M, Yagi K. Biomechanical rationale for a single implantretained mandibular overdenture: an in vitro study. Clin Oral Implants Res. 2008:19:271-275.

23. Alqutaibi AY, Esposito M, Algabri R, Alfahad A, Kaddah A, Farouk M, Alsourori A. Single vs two-implant-retained overdentures for edentulous mandibles: a systematic review. Eur J Oral Implatol. 2017; 10(3):243-261.

24. Takahashi T, Gonda T, Maeda Y. Influence of Reinforcement on Strains Within Maxillary Implant Overdentures. Int $\mathrm{J}$ Oral Maxillofac Implants. 2015;30:1327-1332.

25. Oh TJ, Yoon J, Misch CE, Wang HL. The causes of early implant bone loss: myth or science? J Periodontol. 2002; 73(3):322-33. 
26. Nakhaei M, Dashti H, Baghbani A, Ahmadi Z. Bond strength of locator housing attached to denture base resin secured with different retaining materials. Dental Research Journal. 2020; 17(1):34-39.

27. Desrosiers J, Bravo G, Hébert R, Dutil E, Mercier L. Validation of the box and block test as a mesure of dexterity of elderly people: reliability, validity and norms studies. Arch Phys Med Rehabil. 1994; 75:751-755.

28. Desrosiers J, Hébert R, Bravo G, Rochette A. Age-related changes in upper extremity performance of elderly people: a longitudinal study. Exp Gerontol.1999 Jun;34(3):393-405.

29. Berger S, Porell F. The association between low vision and function. J Aging Health. 2008 Aug;20(5):504-25.

30. Padmanabhan $\mathrm{H}$, Kumar SM, Kumar VA. Single implant retained overdenture treatment protocol: a systematic review and meta-analysis. J Prosthodont. 2020;29(4):287-297.

31. Gonda T, Dong J, Maeda Y. Stress analysis of an overdenture using the finite element method. Int J Prosthodont. 2013 Jul-Aug;26(4):340-2.

32. Grageda E, Rieck B. Metal-reinforced single implant mandibular overdenture retained by an attachment: a clinical report. J Prosthet Dent. 2014 Jan;111(1):16-9.

33. Zappini G, Kammann A, Wachter W. Comparison of fracture tests of denture base materials. J Prosthet Dent. 2003 Dec;90(6):578-85. 
Table 1. Main characteristics of the study sample.

\begin{tabular}{|c|c|c|}
\hline & Categories & $\mathrm{n}(\%)$ \\
\hline \multirow[t]{2}{*}{ Gender } & Female & $99(65.1)$ \\
\hline & Male & $53(34.9)$ \\
\hline \multirow[t]{4}{*}{ Age groups (years) } & $<55$ & $19(12.5)$ \\
\hline & $55-<65$ & $61(40.1)$ \\
\hline & $65-<75$ & $50(32.9)$ \\
\hline & 75 or older & $22(14.5)$ \\
\hline \multirow[t]{3}{*}{ Follow-up time (years) } & $\leq 2$ & $75(49.3)$ \\
\hline & $2-5$ & $47(30.9)$ \\
\hline & $>5$ & $30(19.8)$ \\
\hline \multirow[t]{5}{*}{ Edentulous ridge form } & High well-rounded & $30(19.7)$ \\
\hline & Regular & $40(26.3)$ \\
\hline & High knife-edge & $25(16.4)$ \\
\hline & Flat or depressed & $46(30.3)$ \\
\hline & Not recorded & $11(7.2)$ \\
\hline \multirow{3}{*}{$\begin{array}{l}\text { Retention systems (retentive } \\
\text { caps - height } x \text { diameter) }\end{array}$} & Type I (4.0 x 4.3 mm) & $83(54.6)$ \\
\hline & Type II $(2.1$ x $4.5 \mathrm{~mm})$ & $32(21.1)$ \\
\hline & Type III $(3.2 \times 3.6 \mathrm{~mm})$ & $37(24.3)$ \\
\hline \multirow[t]{3}{*}{ Implant loading protocol } & Immediate & $67(44.1)$ \\
\hline & Early & $37(24.3)$ \\
\hline & Delayed & $48(31.6)$ \\
\hline
\end{tabular}


Table 2. Main characteristics of the overdenture fractures (68 fractures in 49 participants).

\begin{tabular}{llc}
\hline & Categories & $\mathrm{n}(\%)$ \\
\hline \multirow{3}{*}{ Occurrence of fracture } & No & $103(67.8)$ \\
& Yes & $49(32.2)$ \\
Number of fractures & 0 & $103(67.8)$ \\
Time of follow-up & 1 & $32(21.1)$ \\
& 2 & $13(8.6)$ \\
& 3 & $3(2.0)$ \\
Position of the fracture line & Midline quartile & $7(10.3)$ \\
& 2nd quartile & $14(20.6)$ \\
& 3rd quartile & $19(27.9)$ \\
& 4th quartile & $28(41.2)$ \\
& Noteral recorded & $59(86.8)$ \\
& & $4(5.9)$ \\
& & $5(7.4)$ \\
& During function & $29(42.6)$ \\
& Denture dropping & $25(36.8)$ \\
& Improper handling & $5(7.4)$ \\
& Not reported & \\
& &
\end{tabular}


Table 3. Temporal life table for the patients included in the cohort $(n=152)$.

\begin{tabular}{|c|c|c|c|c|c|c|}
\hline Interval start time & $\begin{array}{c}\text { Number of } \\
\text { patients entering } \\
\text { interval }^{*}\end{array}$ & Censored & $\begin{array}{c}\text { Number exposed } \\
\text { to } \text { risk }^{(1)}\end{array}$ & $\begin{array}{l}\text { Incidence of } \\
\text { fracture }\end{array}$ & $\begin{array}{c}\text { Proportion } \\
\text { terminating }\end{array}$ & $\begin{array}{l}\text { Probability } \\
\text { Density }{ }^{(3)}\end{array}$ \\
\hline 0 & 171 & 7 & 167.5 & 25 & 0.15 & 0.012 \\
\hline 1 year & 139 & 51 & 113.5 & 18 & 0.16 & 0.011 \\
\hline 2 years & 70 & 13 & 63.5 & 12 & 0.19 & 0.011 \\
\hline 3 years & 45 & 15 & 37.5 & 8 & 0.21 & 0.010 \\
\hline 4 years & 22 & 2 & 21.0 & 4 & 0.19 & 0.007 \\
\hline 5 years & 16 & 11 & 10.5 & 1 & 0.10 & 0.003 \\
\hline 6 years & 4 & 4 & 2.0 & 0 & 0.0 & 0.000 \\
\hline
\end{tabular}

* The initial 171 cases correspond to the additional time cycles for patients with multiple fractures $(13+6$ time cycles).

(1) Number Exposed to Risk: the number of surviving cases minus one half the censored cases (to account for the effect of the censored cases);

(2) Proportion Terminating: the ratio of terminal events to the number exposed to risk;

(3) Probability Density: an estimate of the probability of experiencing the terminal event during the interval. 


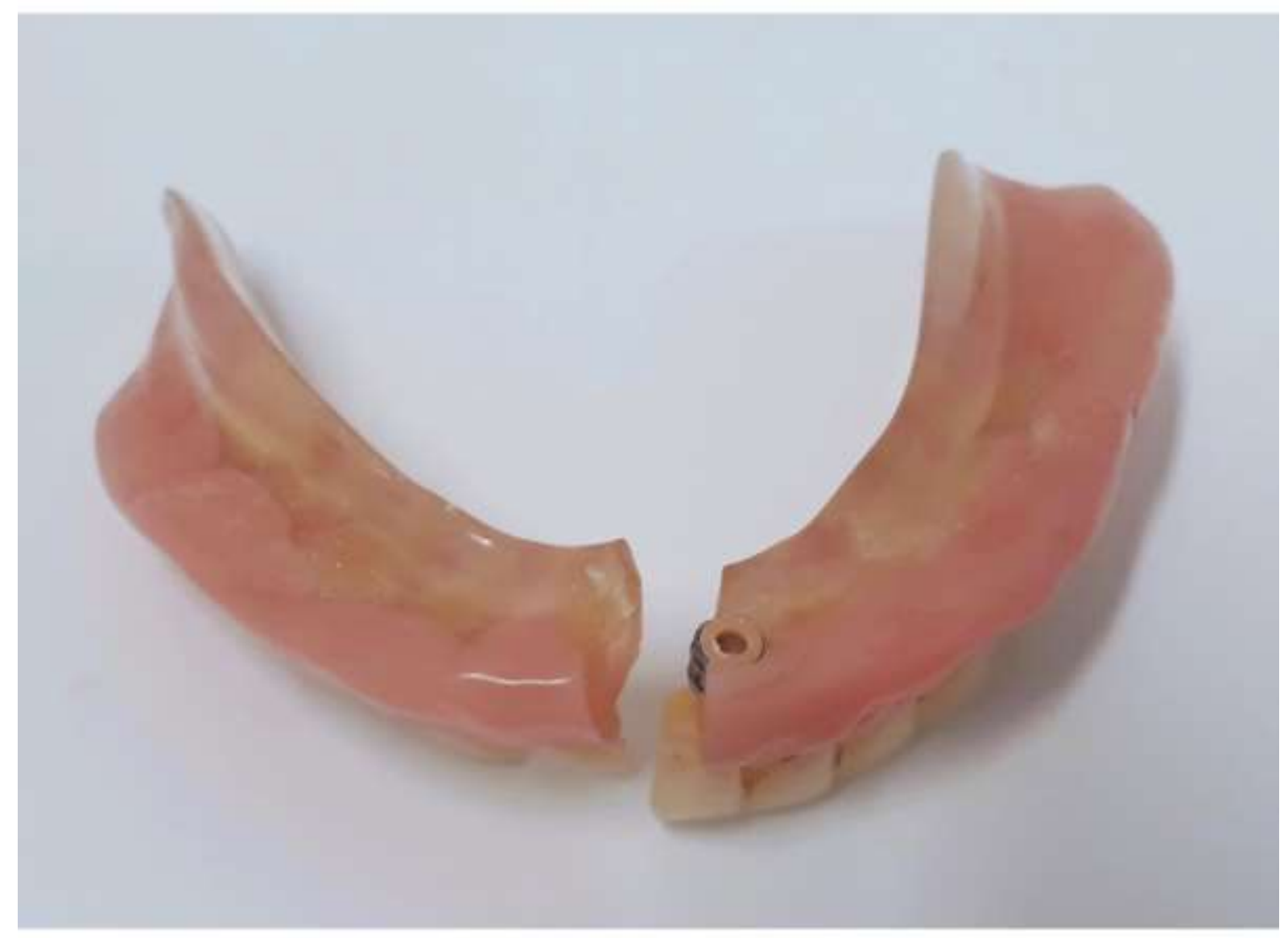

Figure 1. Midline fracture of a single-implant mandibular overdenture. 


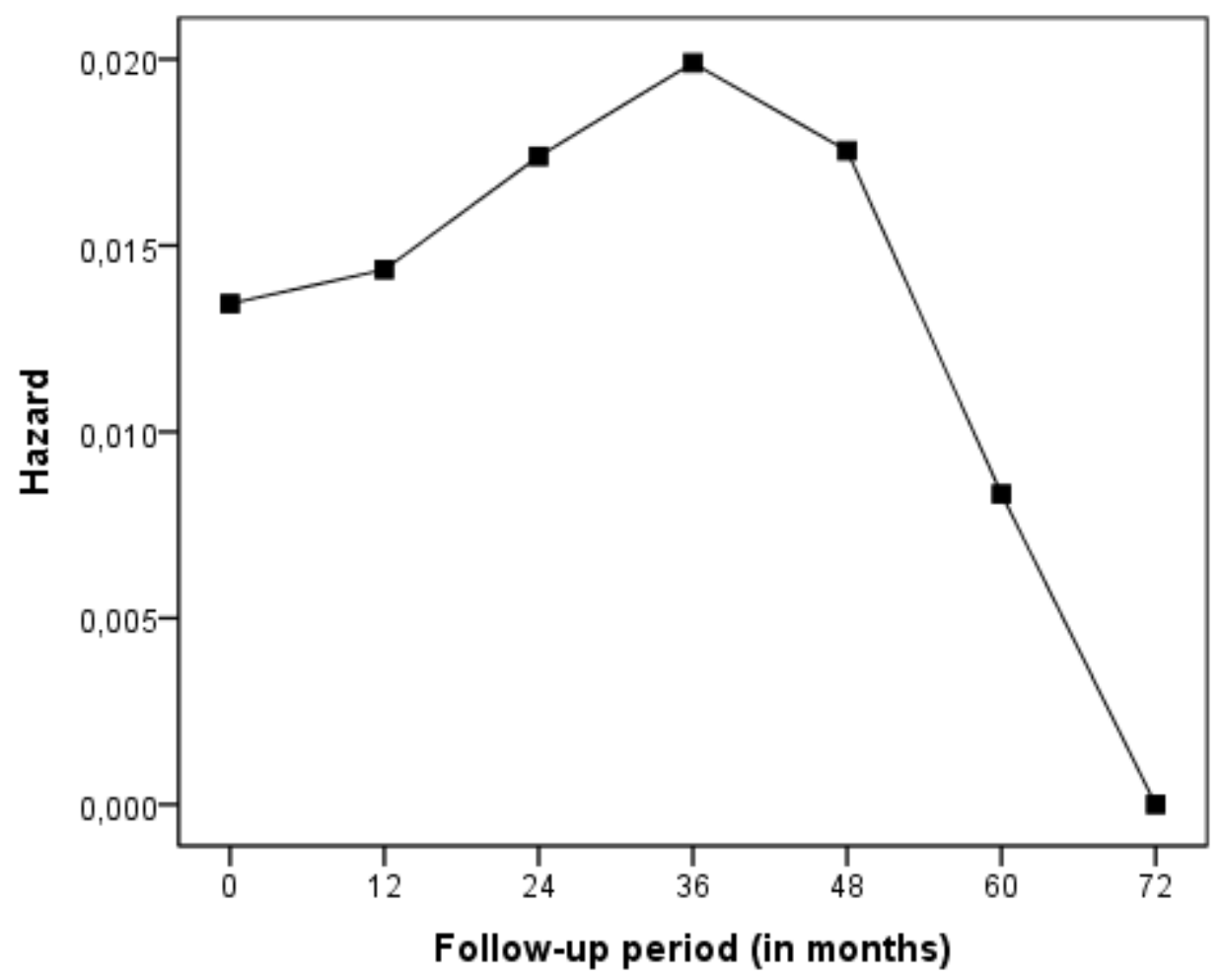

Figure 2. Hazard Rate Function: an estimate of experiencing the terminal event (overdenture fracture) during the interval, conditional upon surviving to the start of the interval. The hazard rates were calculated by dividing the number of fractures per patient/month by the average number of patients without fractures at the interval midpoint. 


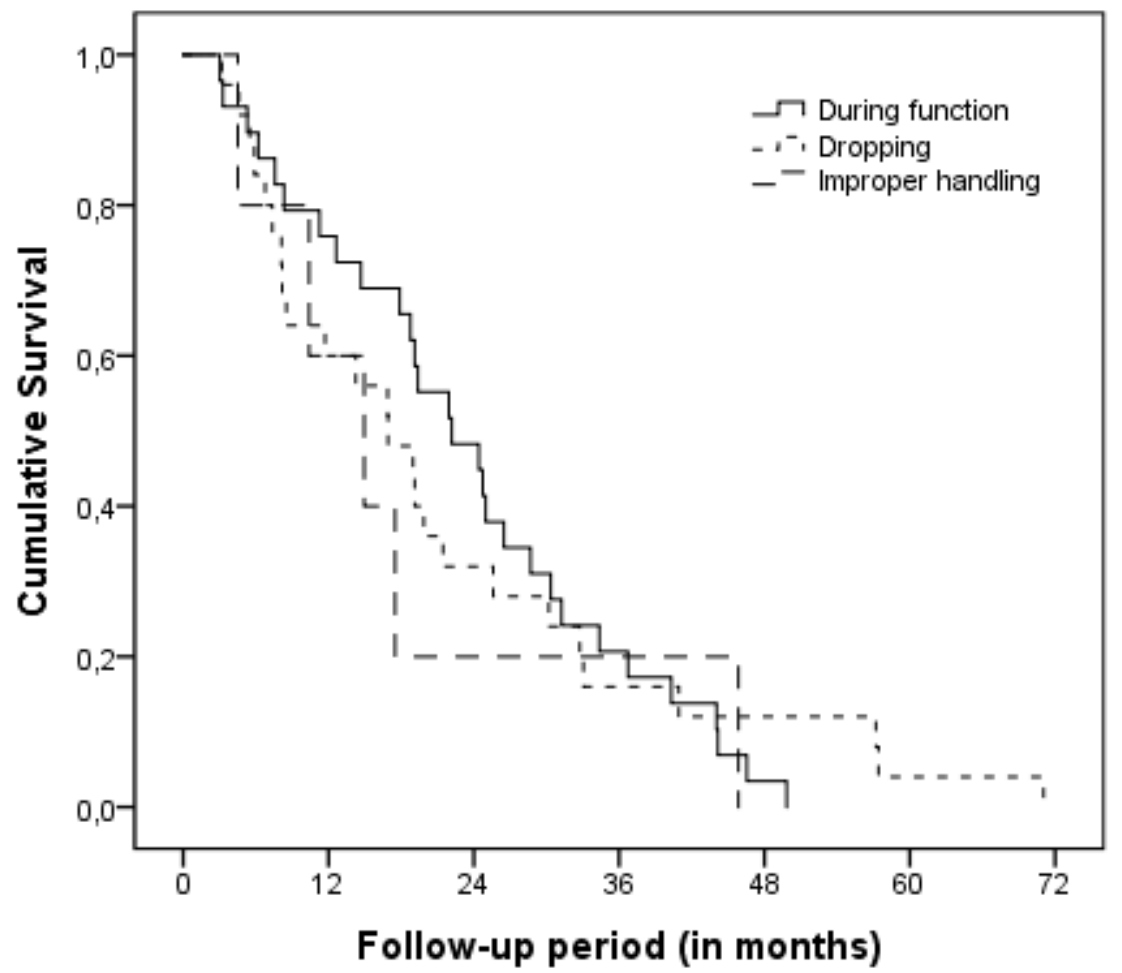

Figure 3. Kaplan-Meier survival curves according to the reported reason for the overdenture fracture. 